\title{
Development of optical parametric amplifier for lidar measurements of trace gases on Earth and Mars \\ Kenji Numata, ${ }^{\mathrm{l}, \text { }}$, Haris Riris, Steve Li, Stewart Wu, Stephan R. Kawa, Michael Krainak, James \\ Abshire \\ ${ }^{a}$ Dept. of Astronomy, Univ. of Maryland, College Park MD, USA 20742 \\ NASA Goddard Space Flight Center, Greenbelt MD, USA 20771
}

\begin{abstract}
Trace gases in planetary atmospheres offer important clues as to the origins of the planet's hydrology, geology, atmosphere, and potential for biology. We report on the development effort of a nanosecond-pulsed optical parametric amplifier (OPA) for remote trace gas measurements for Mars and Earth. The OPA output light is single frequency with high spectral purity and is widely tunable both at $1600 \mathrm{~nm}$ and $3300 \mathrm{~nm}$ with an optical-optical conversion efficiency of $\sim 40 \%$. We demonstrated open-path atmospheric measurements of $\mathrm{CH}_{4}(3291 \mathrm{~nm}$ and $1651 \mathrm{~nm}), \mathrm{CO}_{2}(1573 \mathrm{~nm}), \mathrm{H}_{2} \mathrm{O}$ $(1652 \mathrm{~nm})$ with this laser source.
\end{abstract}

Keywords: Optical Parametric Amplifier, Lidar, DIAL, Space Instrumentation

\section{INTRODUCTION}

Laser remote sensing measurements of trace gases from orbit can provide unprecedented information about important planetary science and answers to critical questions on planetary atmospheres. Carbon dioxide $\left(\mathrm{CO}_{2}\right)$ and methane $\left(\mathrm{CH}_{4}\right)$ are very important greenhouse gases on Earth. Remote sensing of these gases will assist in understanding Earth climate change and reducing the uncertainty in the carbon budget. NASA's decadal survey [1] called for a mission to measure $\mathrm{CO}_{2}, \mathrm{CH}_{4}$ and carbon monoxide $(\mathrm{CO})$. Remote measurements of $\mathrm{CH}_{4}$, water $\left(\mathrm{H}_{2} \mathrm{O}\right)$, and other biogenic molecules (such as ethane and formaldehyde) on Mars have important connections to questions related to the existence of life on Mars [2]. If localized, areas with higher gas concentrations will become a primary target of future lander missions. In order to map these gases globally through differential absorption lidar (DIAL) measurements with much higher accuracies, we are developing a near-infrared (NIR) and mid-infrared (MIR) lidar transmitter. Most Earth and Mars trace gases have suitable spectral absorption features in the NIR $(1.5 \mu \mathrm{m} \sim 1.6 \mu \mathrm{m})$ and the MIR $(3 \mu \mathrm{m} \sim 4 \mu \mathrm{m})$ regions, respectively. Using our tunable laser transmitter and high sensitivity detectors at NIR and/or MIR in a sounding (surface reflection) mode enables DIAL measurements from orbit with modest laser power.

For both Mars and Earth applications, we have developed a laser transmitter system at the NASA Goddard Space Flight Center (GSFC). Our system is based on a nanosecond-pulsed optical parametric amplifier (OPA) pumped at $1064 \mathrm{~nm}$ with magnesium oxide-doped periodically-poled lithium niobate (MgO:PPLN) as the non-linear medium. The OPA is suited for this application since it has sufficient wavelength tuning range for gas detections and it generates both NIR and MIR, where there is no traditional laser that has high spectral purity, sufficient pulse energy, and tuning capability. The output wavelength tuning can be performed by tuning a seed laser in the OPA. While our primary target is $\mathrm{CH}_{4}$ on Earth and Mars, the OPA approach will allow a new capability for general planetary lidar instruments.

While many gas sensing lidar systems are based on optical parametric oscillator (OPO) approach [3 7], our OPA approach is simpler, especially when narrow-linewidth, high-power pump and seed lasers are available. Due to the optical feedback provided by the resonant cavity, OPO generally offers higher output beam quality and narrower output linewidth. However, it is sensitive to alignment, does not allow easy continuous tuning, and requires more optics, electronics, and frequent adjustment. High nonlinearity of quasi-phase matched device (such as PPLN) allows efficient generation of NIR and MIR lights even with the single-pass OPA configuration. Although we have pursued the OPO approach [8], we think the simplicity and robustness of the OPA's optical arrangement is more suitable for space applications. While such a single-pass device used to require high pump peak power with pico-seconds of pulse width.

\footnotetext{
kenji.numata@nasa.gov; phone 1 301-286-0799
} 
nano-second pulse lengths are required for gas sensing applications in order to have narrower transform-limited linewidths to resolve target gas lines. Such a nano-second OPA system based on PPLN has been realized mainly by Nd:YAG microchip lasers [9 12].

In this paper, we report on the setup of the developed OPA system and measurements of diurnal variation of Earth's atmospheric $\mathrm{CH}_{4}, \mathrm{CO}_{2}$, and $\mathrm{H}_{2} \mathrm{O}$ using horizontal absorption paths.

\section{EXPERIMENTAL SETUP}

\subsection{Overview}

We have built two OPA systems, named OPA system 1 and OPA system 2 in this paper. Figure 1 shows the experimental diagram of OPA system 1. In this OPA system 1, both signal $(1573.3 \mathrm{~nm})$ and idler $(3291.1 \mathrm{~nm})$ are used for the simultaneous measurements of $\mathrm{CH}_{4}$ and $\mathrm{CO}_{2}$ using the near and far targets (as shown in Fig. 2), respectively. A nonlinear crystal is pumped by a pulsed $1064 \mathrm{~nm}$ laser and seeded by a continuous-wave distributed-feedback (DFB) laser diode (LD) through a fiber amplifier. Although OPA system 2 has similar setup, only the signal wavelength near $1651 \mathrm{~nm}$ is used for $\mathrm{CH}_{4}$ and $\mathrm{H}_{2} \mathrm{O}$ measurements using the far target. There is no fiber amplifier for the seed in OPA system 2 . Table 1 summarizes technical data of the two OPA lidar systems.

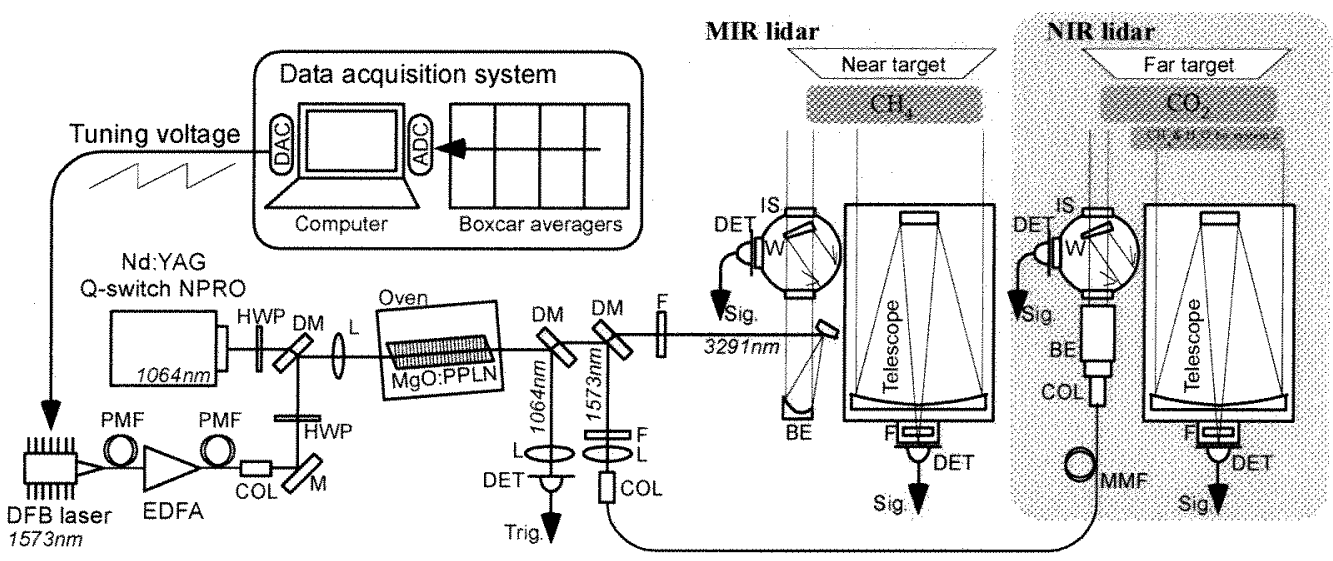

Figure 1. Experimental diagram. A MgO:PPLN crystal is pumped and seeded by a Q-switch Nd:YAG NPRO and a DFB laser, respectively. In OPA system 1 (1573 $\mathrm{mm}$ seed), both signal and idler are used for lidar measurement as shown in this figure. In OPA system 2 (1651 nm seed), only signal is used for lidar measurement and there is no EDFA and MIR lidar. EDFA: Erbium-doped fiber amplifier, HWP: half wave-plate, $\mathrm{M}$ : mirror, DM: dichroic mirror, L: lens, F: wavelength-selecting filter, COL: fiber collimator, IS: integrating sphere, W: wedge, DET: detector, $\mathrm{BE}$ : beam expander, PMF: single-mode polarization maintaining fiber, $\mathrm{MMF}$ : multi-mode fiber, $\mathrm{ADC}$ : analog-to-digital converter, DAC: digital-to-analog converter, Trig: trigger signal for boxcar averagers, Sig: Signal input for boxcar averager

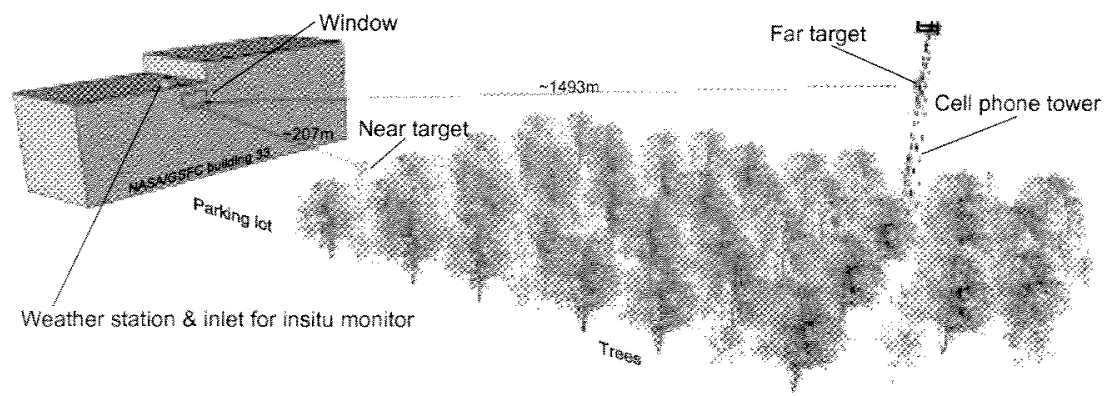

Figure 2. Schematic view of two open paths. Only the MIR lidar (OPA system 1, idler) used the near target. Other NIR lidars (signals of OPA system 1 and 2) used the far target. 


\begin{tabular}{|c|c|c|c|c|}
\hline & \multicolumn{2}{|c|}{ OPA system 1} & \multicolumn{2}{|c|}{ OPA system 2} \\
\hline $\begin{array}{l}\text { Target gas } \\
\text { Pumping }\end{array}$ & $\mathrm{CH}_{4}(3291.1 \mathrm{~nm})$ & $\mathrm{CO}_{2}(1573.3 \mathrm{~nm})$ & $\mathrm{CH}_{4}(1650.9 \mathrm{~nm})$ & $\mathrm{H}_{2} \mathrm{O}(1652.0 \mathrm{~nm})$ \\
\hline Pump source & \multicolumn{4}{|c|}{ LD-pumped, passively Q-switched, Nd:YAG NPRO } \\
\hline Pump pulse width & \multicolumn{4}{|c|}{$\sim 3.3 \mathrm{nsec}$} \\
\hline Incident pump energy & \multicolumn{4}{|c|}{$\sim 60 \mu$} \\
\hline Repetition rate & \multicolumn{4}{|c|}{$\sim 6 \mathrm{kHz}$} \\
\hline$O P A$ & & & & \\
\hline Non-linear medium & \multicolumn{4}{|c|}{ MgO:PPLN, $50 \mathrm{~mm}(\mathrm{~L}) \times 8 \mathrm{~mm}(\mathrm{~W}) \times 1 \mathrm{~mm}(\mathrm{H}), 5^{\circ}$ agnle-cut, AR coated } \\
\hline Grating period & \multirow{2}{*}{\multicolumn{2}{|c|}{$\begin{array}{l}30.5 \mu \mathrm{m} \\
111.9^{\circ} \mathrm{C}\end{array}$}} & \multicolumn{2}{|c|}{$31.0 \mu \mathrm{m}$} \\
\hline Temperature & & & & \\
\hline Beam radius & \multicolumn{4}{|c|}{$\sim 100 \mu \mathrm{m}$ for pump, $\sim 120 \mu \mathrm{m}$ for seed } \\
\hline Output pulse width & \multicolumn{4}{|c|}{$\sim 2 \mathrm{nsec}$} \\
\hline Output energy & $\sim 7.6 \mu$ & $\sim 16 \mu$ & \multicolumn{2}{|c|}{$\sim 13 \mu$} \\
\hline $\begin{array}{l}\text { Output linewidth } \\
\text { Seeding }\end{array}$ & \multicolumn{4}{|c|}{$\sim 500 \mathrm{MHz}$} \\
\hline Seed laser & \multicolumn{4}{|c|}{ Telecom DFB LD, PM fiber coupled } \\
\hline Wavelength & \multicolumn{2}{|c|}{$1573.3 \mathrm{~nm}$} & \multirow{2}{*}{\multicolumn{2}{|c|}{$\begin{array}{c}1650.9 \mathrm{~nm} / 1652.0 \mathrm{~nm} \text { (temperature tuned) } \\
\text { Not used }\end{array}$}} \\
\hline Amplifier & \multicolumn{2}{|c|}{ PM EDFA } & & \\
\hline Seed power & & & \multicolumn{2}{|c|}{$\sim 15 \mathrm{~mW}$} \\
\hline Scan & \multicolumn{4}{|c|}{$2 \mathrm{~Hz}$, ramped, current tuning } \\
\hline Transmitter & & & \multicolumn{2}{|l|}{ (2) } \\
\hline Integrated sphere coating & Infragold & Spectralon & \multicolumn{2}{|c|}{ Spectralon } \\
\hline Beam expander & Reflective & Refractive & \multicolumn{2}{|c|}{ Refractive } \\
\hline $\begin{array}{l}\text { Wedge material } \\
\text { Receiver }\end{array}$ & $\mathrm{CaF}_{2}$ & BK7 & \multicolumn{2}{|c|}{ BK7 } \\
\hline Telescope & \multicolumn{4}{|c|}{ 200-mm diameter, Cassegrain } \\
\hline Detector & HgCeTe & InGaAs & & \\
\hline
\end{tabular}

Table 1. Technical data of the OPA lidar system.

\subsection{OPA source}

The pump source is a passively Q-switched, Nd:YAG non-planar ring oscillator (NPRO) made by Innolight Inc. (Germany) that emits single-frequency, single longitudinal-mode output at $1064.5 \mathrm{~nm}$. It has 3.3-nsec pulse width and $60-\mu \mathrm{J}$ energy at about $6-\mathrm{kHz}$ repetition rate. The optical linewidth of the NPRO is transform limited $(-133 \mathrm{MHz})$.

The seed source is a continuous-wave, PM (polarization-maintaining) fiber-coupled, DFB LD. The linewidth of DFB LD is less than $1 \mathrm{MHz}$. The wavelengths of the DFB LDs are selected to be $1573.3 \mathrm{~nm}$ and $1651 \mathrm{~nm}$ for OPA system 1 and system 2, respectively. The 1651-nm LD for OPA system 2 is step-scanned between $1650.9 \mathrm{~nm}$ and $1652.0 \mathrm{~nm}$ for $\mathrm{CH}_{4}$ and $\mathrm{H}_{2} \mathrm{O}$ measurements, respectively, by applying step temperature change of $7.2{ }^{\circ} \mathrm{C}$ with an interval of 5 minutes. The DFB LD can be smoothly tuned through a wide range $(>0.25 \mathrm{~nm}$ or $30 \mathrm{GHz})$ without a mode hop through injection current modulation. As a result, the output idler and signal can be tuned without a mode hop across the absorption peaks of the target gases. The two seed LDs for the two systems are tuned simultaneously by a common ramp voltage at $2 \mathrm{~Hz}$. We observed that use of higher seed optical power ensures smooth tuning as well as high efficiency. When the seed has low power and a slight misalignment, the signal was obscured by the amplified vacuum fluctuation and/or a parasitic parametric oscillation. Therefore, we used a minimum seed power of $\sim 15 \mathrm{~mW}$. For OPA system 1 at $1573.3 \mathrm{~nm}$, we amplified the seed to $\sim 300 \mathrm{~mW}$ using a PM Erbium-doped fiber amplifier (EDFA).

The seed beam is co-aligned to the pump by a dichroic mirror. The beams are focused down to a crystal by a lens with focal length of $300 \mathrm{~mm}$. The resultant beam radii inside the crystal are $\sim 100 \mu \mathrm{m}$ and $\sim 125 \mu \mathrm{m}$ for the pump and the seed, respectively. The locations of the beam waists are carefully adjusted to overlap with each other. With this pump beam size, the crystal is operated near the threshold of optical parametric generation (OPG). 


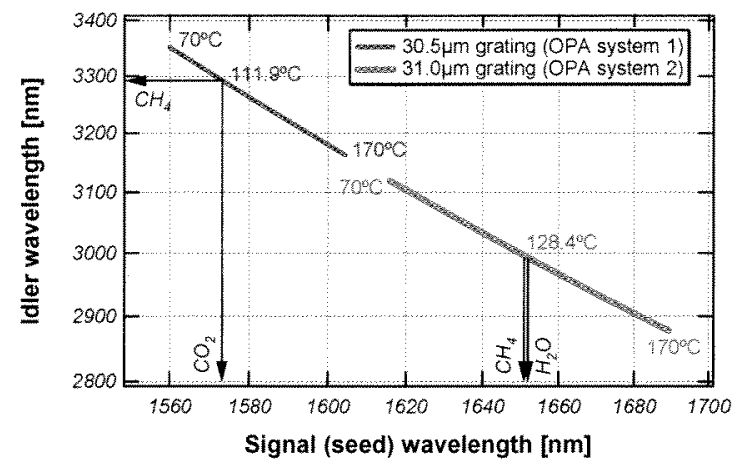

Figure 3. Tuning curves of the two MgO:PPLN crystals used in the two OPA systems,

The nonlinear crystal is $50-\mathrm{mm}$ long, $1-\mathrm{mm}$ thick MgO:PPLN. The end surfaces of the crystal were angled at $5^{\circ}$ and anti-reflective coated at the pump, the signal, and the idler wavelengths, in order to minimize the optical feedback due to reflections. A similar angle-cut crystal arrangement can be found, for example, in [13]. We observed that the output signal/idler wavelengths do not follow the scanned seed smoothly, when there was no angled end. Figure 3 shows measured tuning curve of the MgO:PPLN crystal. We used $30.5-\mu \mathrm{m}$ grating at $111.9^{\circ} \mathrm{C}$ and $31.0-\mu \mathrm{m}$ grating at $128.4^{\circ} \mathrm{C}$, for the OPA system 1 and 2, respectively. Center wavelength of parametric gain at NIR was tunable between 1560 and $1690 \mathrm{~nm}$, with the two gratings, by tuning temperature between 70 and $170^{\circ} \mathrm{C}$. Corresponding idler tuning range was $2780 \sim 3350 \mathrm{~nm}$. The full-width half-maximum of the unseeded OPG spectra was about $2 \mathrm{~nm}$ at NIR. As a result, there was no need to tune the crystal temperature for the two wavelengths $(1650.9 \mathrm{~nm}$ and $1652.0 \mathrm{~nm})$ in the OPA system 2 . Once seeded within the gain bandwidth, the output spectrum collapsed to the seed wavelength with $>20 \mathrm{~dB}$ suppression.

\subsection{Lidar and monitor systems}

The output beam is separated into three paths using dichroic mirrors. The signal at NIR and the idler at MIR are used for gas detection through open-paths with cooperative hard targets set at $1493 \mathrm{~m}$ and $207 \mathrm{~m}$ away, respectively, as shown in Fig. 2. The metal targets are covered by automotive reflective tape. The signal and the idler are detected by InGaAs and HgCdTe detectors, respectively. The light goes through a beam expander and a wedge, which is set inside the integrating sphere. The scattered light inside the integrating sphere is detected by a detector and used as an energy monitor to normalize the return signals. The return beams reflected by the hard targets are received by 20 -cm Cassegrain telescopes with protective aluminum coatings. The pulsed signals from the detectors are averaged by boxcar averagers triggered by the residual pump pulse. In order to avoid optical crosstalk, optical filters are inserted before the transmitter and after the telescope.

In order to monitor temperature and pressure of the atmosphere, which are needed to convert the measured absorption curve into mixing ratios, a weather station is set at the roof of our building. An in-situ device built by Picarro Inc. (USA) monitored $\mathrm{CH}_{4}, \mathrm{CO}_{2}$, and $\mathrm{H}_{2} \mathrm{O}$ mixing ratios of the outside air at the same roof. The two lidar systems and the in-situ system are set at $4^{\text {th }}$ floor of one of the buildings at GSFC, in Greenbelt, MD, and are operated simultaneously.

\section{EXPERIMENTAL RESULTS}

\subsection{OPA characterization}

Figure 4 shows the relationship between pump energies, signal energies, and seed powers in OPA system 1. With a 60 $\mu \mathrm{J}$ pump and a $-300-\mathrm{mW}$ seed at $1573.3 \mathrm{~nm}$, we got $\sim 16-\mu \mathrm{J}$ signal, excluding the effect of $\sim 70-\%$ transmittance of wavelength selection filter. Corresponding idler at $3291.1 \mathrm{~nm}$ was $\sim 7.6 \mu \mathrm{J}$. Thus, total pump conversion efficiency was $(16 \mu \mathrm{J}+7.6 \mu \mathrm{J}) / 60 \mu \mathrm{J}-39 \%$. 


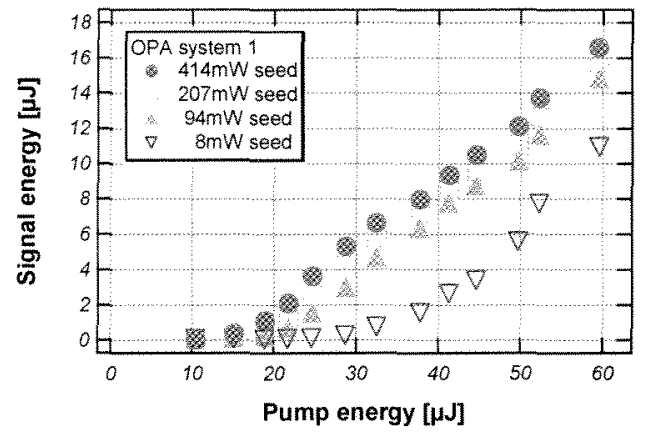

Figure 4. Relationship between signal and pump energies at different seed power levels (OPA system 1).

The OPA outputs (signal and idler) had $\sim 2-n s e c$ width and distorted Gaussian pulse shape, which is caused by the backconversion process between the 1064-nm pump and signal/idler. The $\mathrm{M}^{2}$ of the OPA output signal beam was $\sim 1.3$. The output linewidth of the OPA was estimated both from scanning Fabry-Perot etalon and gas cells. When the pump energy was low and the crystal was operated near the differential frequency generation (DFG) regime, the linewidth of signal was measured to be near transform limited $(<200 \mathrm{MHz})$. When the pump energy was high and at our nominal OPA operating condition, it was broadened to $-500 \mathrm{MHz}$ (averaged over the beam) due to the back-conversion processes. The effect of the broadened linewidth on the measured mixing ratio was small, since typical full-width half maximum (FWHM) linewidth of our target line is $\sim 5 \mathrm{GHz}$ under Earth's atmospheric pressure ( $\sim 760$ Torr).

\subsection{Open path scans}

The calculation of mixing ratio was done by fitting the scan result with theoretical Voigt profile (examples are shown in Fig. 5). To reduce the statistical error, $5 \mathrm{~min}$ of the digitized data were averaged. As a result, 10 -min interval data of $\mathrm{CH}_{4}$ and $\mathrm{H}_{2} \mathrm{O}$ was alternatively obtained for OPA system 2. The signal from the receiver telescope was divided by the signal from the integrating sphere. The baseline was determined by fitting the divided data excluding the absorption feature with a 5 -th order polynomial function, which removed drifting instrumental fringes. The $\mathrm{CH}_{4}$ and $\mathrm{CO}_{2}$ absorptions are affected by the side lobes of nearby $\mathrm{H}_{2} \mathrm{O}$ absorption lines and may cause error in the mixing ratio estimation. Therefore, the result from the $1652.0-\mathrm{nm} \mathrm{H}_{2} \mathrm{O}$ lidar, which has less contamination from other gas species, was used to correct the baseline of the other lidar data. The data was normalized both by the fitted baseline and by the $\mathrm{H}_{2} \mathrm{O}$ contribution, and finally fitted by the theoretical Voigt profile [14] using a central wavelength of the scan and a mixing ratio as fitting parameters. Measured temperature, pressure, and round-trip path lengths were used to calculate the profile. Line parameters (center wavelength, line strength, etc.) are taken from the HITRAN 2008 database [15]. Nearby $\sim 10$ lines were included into the fitting process.
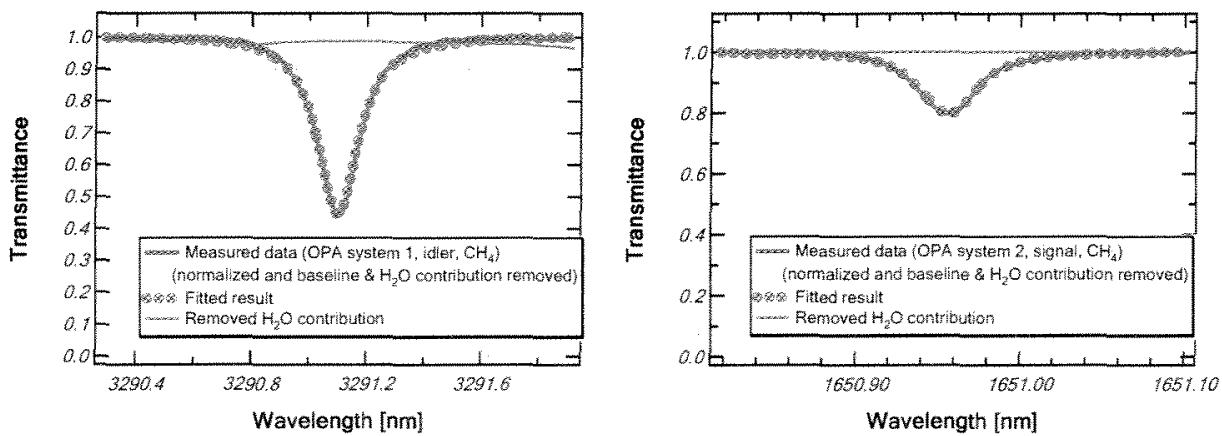

Figure 5. Examples of measured scan data and fitting results. $\mathrm{CH}_{4}$ measurement at $3291.1 \mathrm{~nm}$ (left) and $1650.9 \mathrm{~nm}$ (right) are shown. The scan data was averaged, divided by the signal from the integrating sphere, and further 
normalized by a polynomial baseline determined from the edge of the data, after the removal of the $\mathrm{H}_{2} \mathrm{O}$ contribution.

Figure 6 shows the result of simultaneous measurements of $\mathrm{CH}_{4}, \mathrm{CO}_{2}$, and $\mathrm{H}_{2} \mathrm{O}$ mixing ratio for 50 hours. The lidar measurements showed good agreement with in-situ data for all three gases.
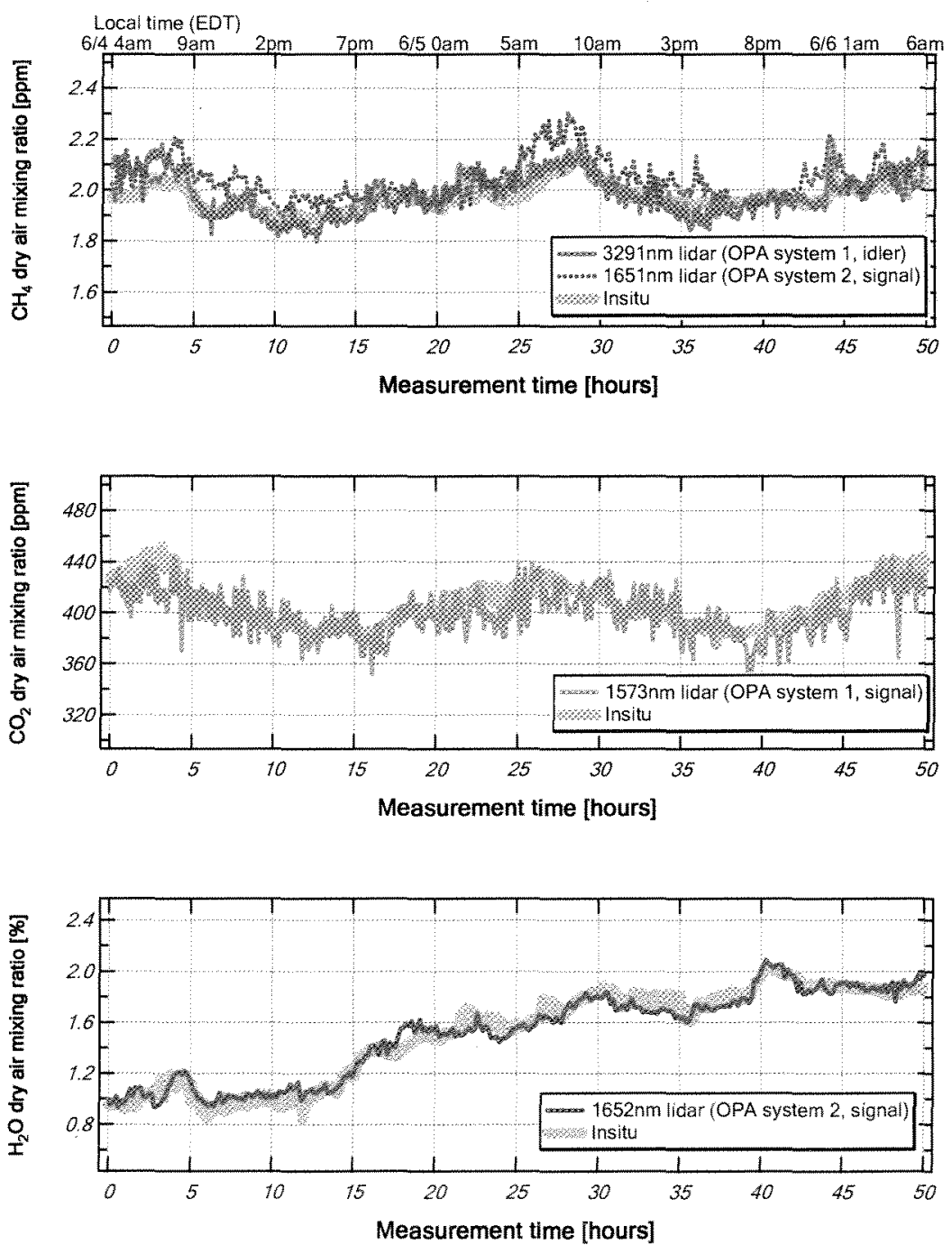

Figure 6. Simultaneous measurements of the diumal variations of atmospheric $\mathrm{CH}_{4}$ (top), $\mathrm{CO}_{2}$ (middle), and $\mathrm{H}_{2} \mathrm{O}$ (bottom) measured with the two OPA lidar systems and an in-situ sensor.

\section{DISCUSSIONS}

\subsection{Interpretation of results}

The agreement between the lidar and the in-situ sensor shows that the OPA system is capable of measuring variations in mixing ratios of the atmospheric gases both at NIR and MIR. Their deviation can be largely explained by the difference 
between the lidar's column measurement and the in-situ device's point measurement. We observed $\pm 1 \mathrm{ppm}$ and $\sim 30 \mathrm{ppm}$ mixing ratio variations in $\mathrm{CH}_{4}$ and $\mathrm{CO}_{2}$ channels, respectively. The methane source is thought to be the power plant at NASA GSFC, which uses natural gas from a nearby landfill. This hypothesis is in part supported by the difference between the two results from the two $\mathrm{CH}_{4}$ channels. The 3291.1-nm channel (OPA system 1, near target) has better agreement to the in-situ data, while the 1650.9-nm channel (OPA system 2, far target) showed excess $\mathrm{CH}_{4}$ when there were increases in it. This difference is possibly caused by the incoming $\mathrm{CH}_{4}$ flow in the pipeline for the power plant. The $\mathrm{CO}_{2}$ variation is equally likely from respiration of vegetation at night. The larger fast fluctuation observed in the $\mathrm{CO}_{2}$ channel is likely from the optical interference between the two ends of multi-mode fiber. The $\mathrm{H}_{2} \mathrm{O}$ channel (OPA system 2, far target) showed the best agreement to in-situ data, especially when there was no air-conditioning activity in the building. The good agreement is obtained partly because of the use of the continuous wavelength data and the removal of instrument baseline drifts.

\subsection{Airborne demonstration}

We upgraded the OPA system 2 to perform an airborne demo of $\mathrm{CH}_{4}$ measurements at $1650.9 \mathrm{~nm}$. A NIR photomultiplier detects a strong return signal from the earth surface from a few $\mathrm{km}$ altitudes. The optics components are mounted on stable, spring-free mounts, and the fiber-coupled beam expander was replaced by a free-space transmitter. Instead of the continuous seed wavelength scan described in this paper, we implemented a stepped scan which samples 20 wavelength points across the $1650.9-\mathrm{nm} \mathrm{CH}_{4}$ line pulse by pulse. The result will be reported after the completion of demo flights scheduled in August, 2011.

\subsection{Power scaling for space implementation}

Since our system is less alignment sensitive, it can be implemented by naturally enhancing existing Nd:YAG space laser instruments. For satellite-based instruments at a few $100-\mathrm{km}$ altitudes, our $\sim 10-\mu \mathrm{J}$ output energy has to be scaled up by a factor of $\sim 100$. In the experiment presented here, our output energy is limited by the pump energy $(\sim 60 \mu \mathrm{J})$. Since this OPA approach should be scalable to a higher output power as long as the crystal is not damaged, we are looking into injection seeded NPROs and burst-mode Yb fiber amplifiers, in order to boost the pump energy to $>1-\mathrm{mJ}$ level. With a $600-\mu \mathrm{J}$ injection-seeded NPRO, we have obtained $\sim 100-\mu \mathrm{J}$ signal output. Using a fiber laser in burst mode is a new concept for OPA power scaling, and it potentially offers higher wall-plug efficiency for space applications. In these high pump energy situations, back-conversion would lead to spectral broadening and may obscure detailed spectral features of low pressure atmospheres. For example, the Doppler width of a $\mathrm{CH}_{4}$ line at $3270.4 \mathrm{~nm}$ is $\sim 240 \mathrm{MHz}$ at $\mathrm{Martian}$ atmosphere $(\sim 5$ Torr at the surface). In order to keep the laser linewidth at least at the same level as the Doppler width, we might need to make our OPA multiple stages and amplify a signal and/or an idler separately, especially for Mars applications, using a longer pump pulse $(\sim 10 \mathrm{nsec})$ and larger beam size inside the crystal.

\section{CONCLUSIONS}

Lidar will be a key technology for the measurement of atmospheric gases on global scales with high sensitivity and resolution, and it will enhance our understanding of the current state of planetary atmospheres and geology. We have demonstrated the ability to detect diurnal variations of atmospheric trace gases both in the NIR and MIR regimes using OPA and cooperative hard targets. Comparative measurements on the $\mathrm{CH}_{4}, \mathrm{CO}_{2}$, and $\mathrm{H}_{2} \mathrm{O}$ variations measured by the OPA systems and the in-situ instrument showed good agreement. Given a sufficient tuning range of the OPA, the measurements can be extended to other molecules. We believe our approach will become a core technology in the future planetary DIAL instruments.

This work is supported by the NASA Astrobiology Program's Astrobiology Science and Technology Instrument Development (ASTID) Program.

\section{REFERENCES}

[1] National Research Council, "Earth Science and Applications from Space: National Imperatives for the Next Decade and Be-yond,"Jan. 2007, available from http:/www.nap.edu/. 
[2] G. L. Villanueva, M. J. Mumma, and R. E. Novak, "Strong release of methane on Mars: Evidence of biology or geology?," 19th Annual VM Goldschmidt Conference, Davos, Switzerland, Geochimica et Cosmochimica Acta, 73, A1384 (2009).

[3] A. Amediek, A. Fix, M. Wirth, and G. Ehret, "Development of an OPO system at $1.57 \mu \mathrm{m}$ for integrated path DIAL measurement of atmospheric carbon dioxide," Applied Physics B, 92, 295 (2008).

[4] R. A. Baumgartner and R. L. Byer, "Continuously tunable ir lidar with applications to remote measurements of $\mathrm{SO}_{2}$ and $\mathrm{CH}_{4}, "$ Applied Optics, 17, 3555 (1978).

[5] M. J. T. Milton, T. D. Gardiner, F. Molero and, J. Galech, "Injection-seeded optical parametric oscillator for rangeresolved DIAL measurements of atmospheric methane," Optics Communications, 142, 153 (1997).

[6] M. Imaki and T. Kobayashi, "Infrared frequency upconverter for high-sensitivity imaging of gas plumes," Optics Letters, 32, $1923(2007)$.

[7] D. Sakaizawa, C. Nagasawa, T. Nagai, M. Abo, Y. Shibata, M. Nakazato, and T. Sakai, "Development of a $1.6 \mu \mathrm{m}$ differential absorption lidar with a quasi-phase-matching optical parametric oscillator and photon-counting detector for the vertical $\mathrm{CO}_{2}$ profile," Applied Optics, 48, 748 (2009).

[8] A. W. Yu, K. Numata, H. Riris, J. B. Abshire, G. Allan, X. Sun, and M. A. Krainak, "Mid-Infrared OPO for high resolution measurements of trace gases in the Mars atmosphere," in Laser Applications to Chemical, Security and Environmental Analysis, OSA Technical Digest (CD) (Optical Society of America), paper LMC5 (2008).

[9] J. Zayhowski, "Periodically poled lithium niobate optical parametric amplifiers pumped by high-power passively Qswitched microchip lasers," Optics Letters, 22, 169 (1997).

[10] K. Aniolek, R. Schmitt, T. Kulp, B. Richman, S. Bisson, and P. Powers, "Microlaser-pumped periodically poled lithium niobate optical parametric generator-optical parametric amplifier," Optics Letters, 25, 557 (2000).

[11] T. J. Kulp, S. E. Bisson, R. P. Bambha, T. A. Reichardt, U. B. Goers, K. W. Aniolek, D. A. V. Kliner, B. A. Richman, K. M. Armstrong, R. Sommers, R. Schmitt, P. E. Powers, O. Levi, T. J. Pinguet, M. M. Fejer, J. P. Koplow, L. Goldberg, T. G. Mcrae, "The application of quasi-phase-matched parametric light sources to practical infrared chemical sensing systems", Applied Physics B, 75, 317 (2002).

[12] T. A. Reichardt, R. P. Bambha, T. J. Kulp, and R. L. Schmitt, "Frequency-Locked, injection-Seeded, pulsed narrowband optical parametric generator," Applied Optics, 42, 3564 (2003).

[13] U. Bäder, T. Mattern, T. Bauer, J. Bartschke, M. Rahm, A. Borsutzky, and R. Wallenstein, "Pulsed nanosecond optical parametric generator based on periodically poled lithium niobate," Optics Communications, 217, 375 (2003).

[14] E. E. Whiting, "An empirical approximation to the Voigt profile," Journal of Quantitative Spectroscopy and Radiative Transfer, 8, 1379 (1968).

[15] L. S. Rothman, et. al., "The HITRAN 2008 molecular spectroscopic database," Journal of Quantitative Spectroscopy and Radiative Transfer, 110,533 (2009). 


\section{Development of optical parametric amplifier for lidar measurements of trace gases on Earth and Mars}

Kenji Numataa Haris Riris, Steve Li, Stewart Wu, Stephan R. Kawa, Michael Krainak, James Abshire

a Dept. of Astronomy, Univ. of Maryland, College Park MD, 20742 NASA Goddard Space Flight Center, Greenbelt MD, 20771 


\section{Abstract}

- Ultimate goal

- Generation of high spatial resolution maps of trace gas

- Understanding atmosphere and geology on Earth and Mars

- OPA transmitter approach

- Many trace gases of interest have strong absorption in NIR (1-2 $\mu \mathrm{m})$ and MIR ( $3-4$ um) bands.

- $1064 \mathrm{~nm}$-pumped OPA can generate both.

- In-house capability in generating NIR/MIR sources

- Demonstrated open-path scan of $\mathrm{CH}_{4}, \mathrm{CO}_{2}, \mathrm{H} 2 \mathrm{O}$ at NIR/MIR using nanosecond OPA

- Confirmed fine tunability and high stability 


\section{Introduction}

- Generation of high spatial resolution maps of trace gas

- Mars \& earth applications

- Laser-based measurement from orbits

- Replacing low-resolution passive spectrometers

- Target trace gases

- Earth

- $\mathrm{CO}_{2}, \mathrm{CH}_{4}$, etc. as greenhouse gases

- Absorptions at NIR wavelengths

- Mars

- $\mathrm{CH}_{4}, \mathrm{H}_{2} \mathrm{O}$, etc. as life indicators

- Absorptions at MIR wavelengths

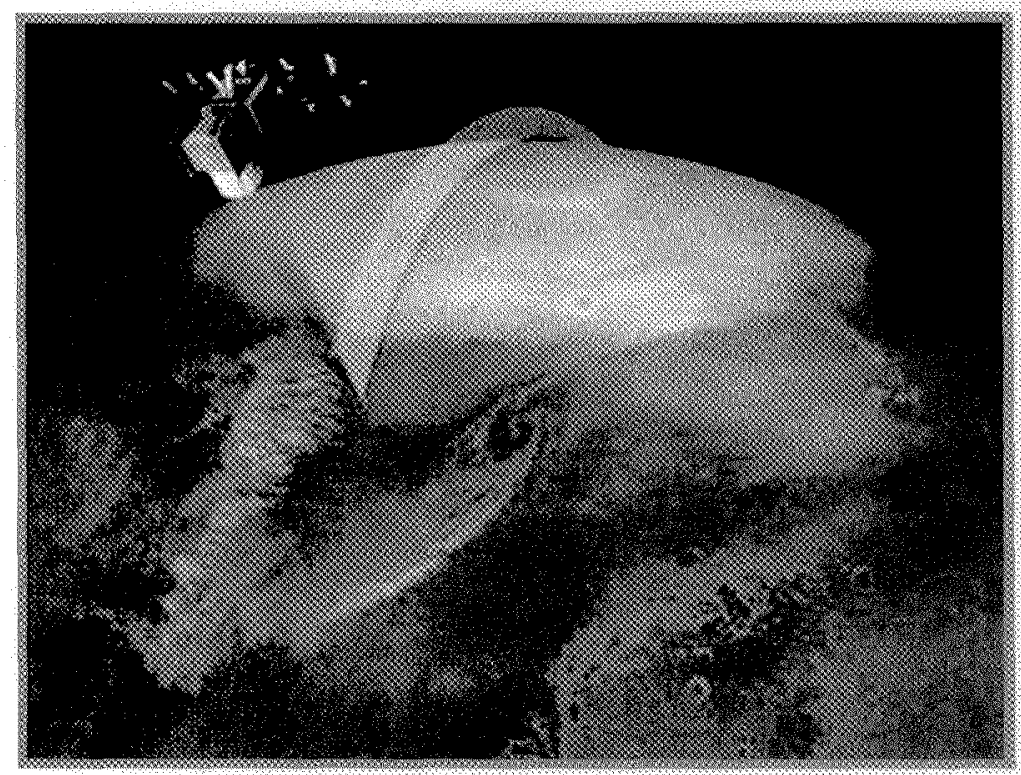




\section{Measurement concept}

- Differential Absorption Lidar (DIAL)

- Receiver measures energy of the laser echoes from surface

- On-line and off-line measurements

- Continuous global coverage

- No need for sunlight

- OPA-based transmitter

- 1064 mm pulsed pump

- Tunable seed

- NIR/MIR outputs

- Simpler than OPO

- Alternative to NIR fiber amp

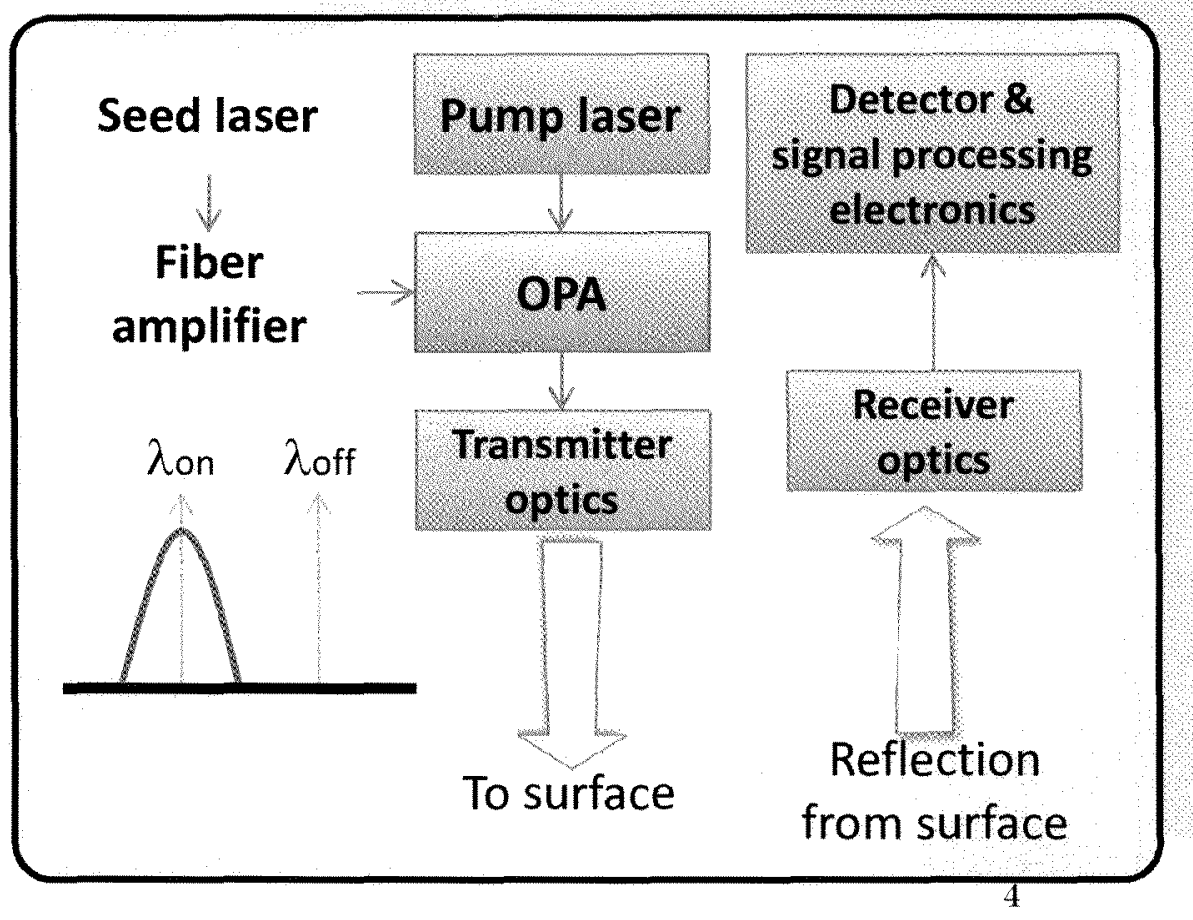




\section{Experimental setup}

- Two OPA systems

- OPA system 1: $\mathrm{CH}_{4}(3291 \mathrm{~nm})$ and $\mathrm{CO}_{2}(1573 \mathrm{~nm})$

- OPA system 2: $\mathrm{CH}_{4}(1651 \mathrm{~nm})$ and $\mathrm{H}_{2} \mathrm{O}(1652 \mathrm{~nm})$

- Pump laser

- 1064nm NPRO (Innolight)

- $\sim 3 n s e d / 6 k H z / 60 \mu$

- Seed laser

- OPA system 1: DFB LD + EDFA (1573nm)

- OPA system 2: DFB LD (1651nm)

- Crystal

- 50-mm PPLN

- Angle-polished to avoid feedbacks

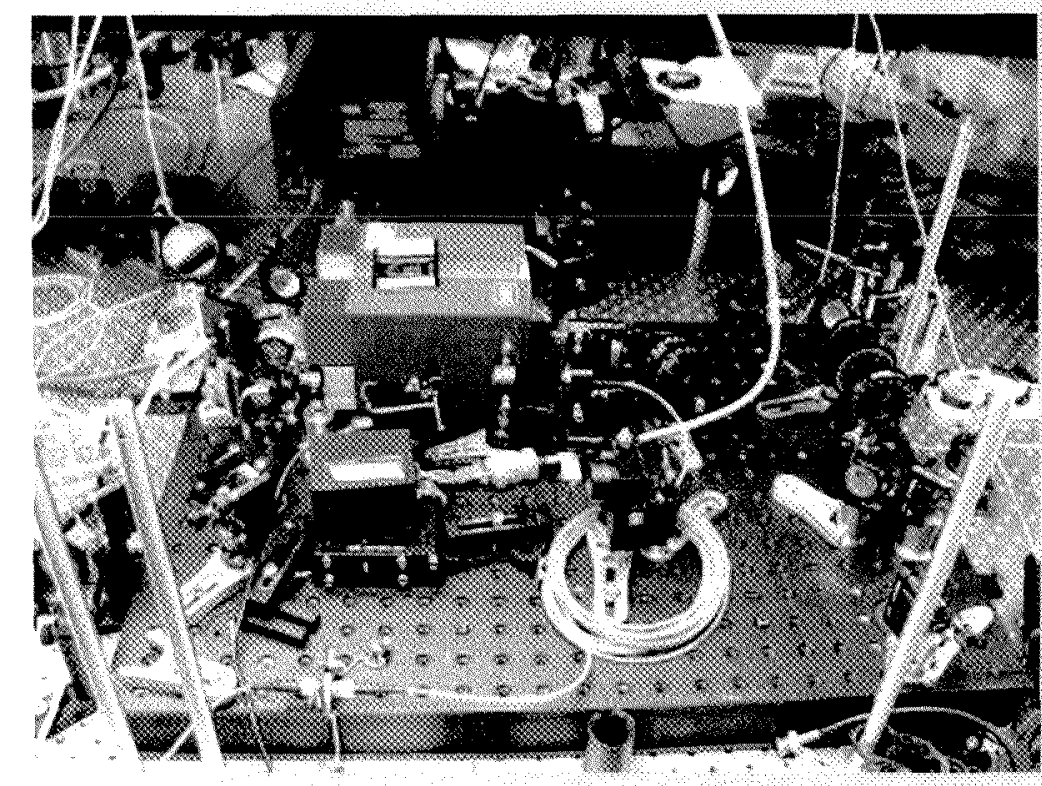

Photo of OPA system 1 


\section{Experimental diagram}

- OPA system 1

- Dual scan at MIR and NIR

- Continuous scan

- Direct detection

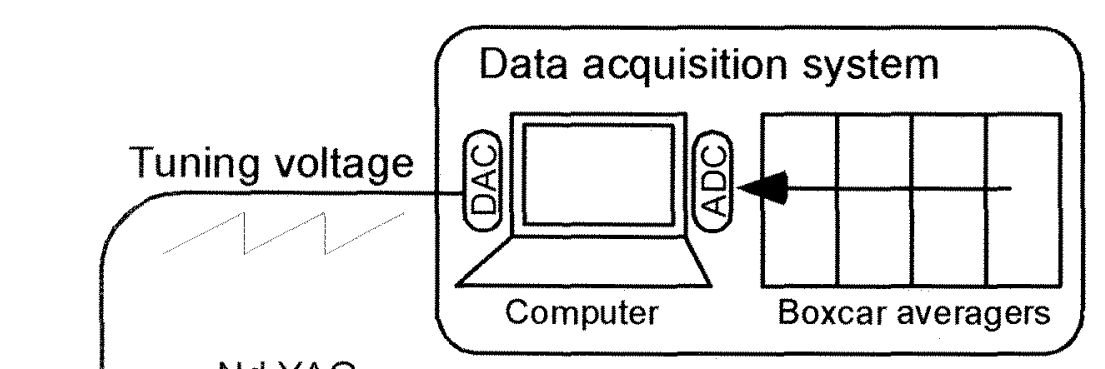

MIR lidar

Nd:YAG
-switch NPRO

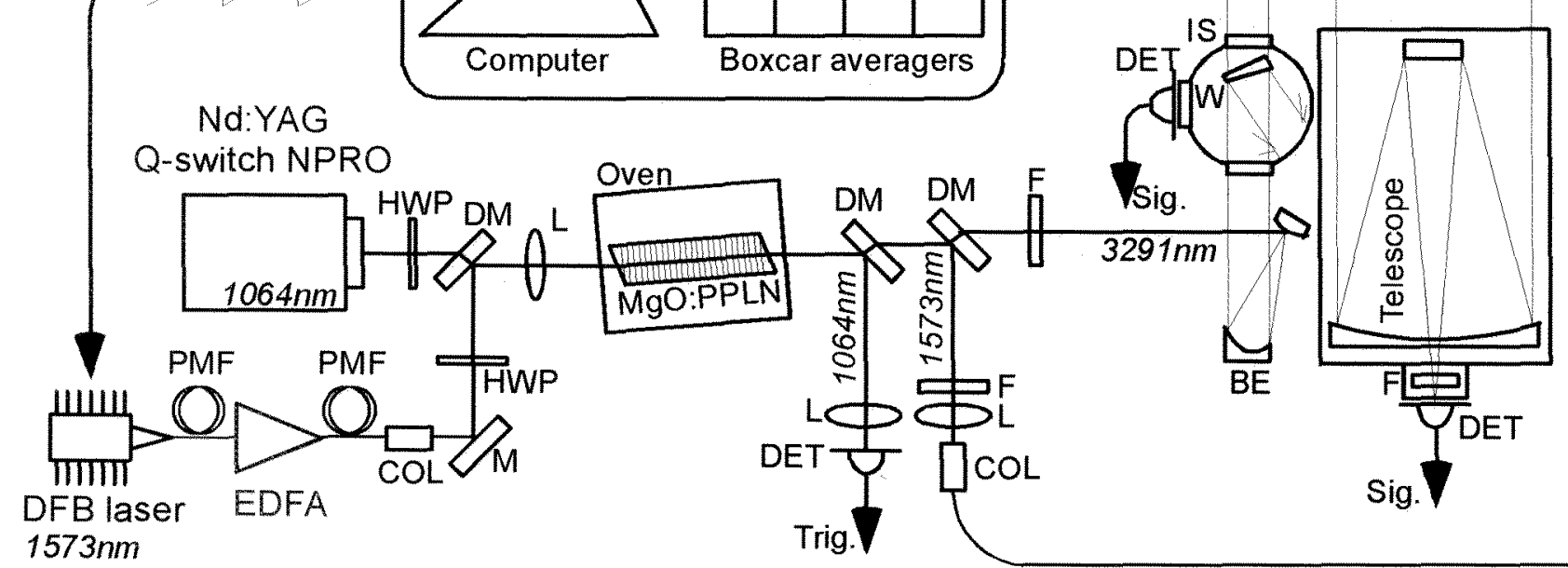

Near target

$\mathrm{CH}_{4}$
NIR lidar

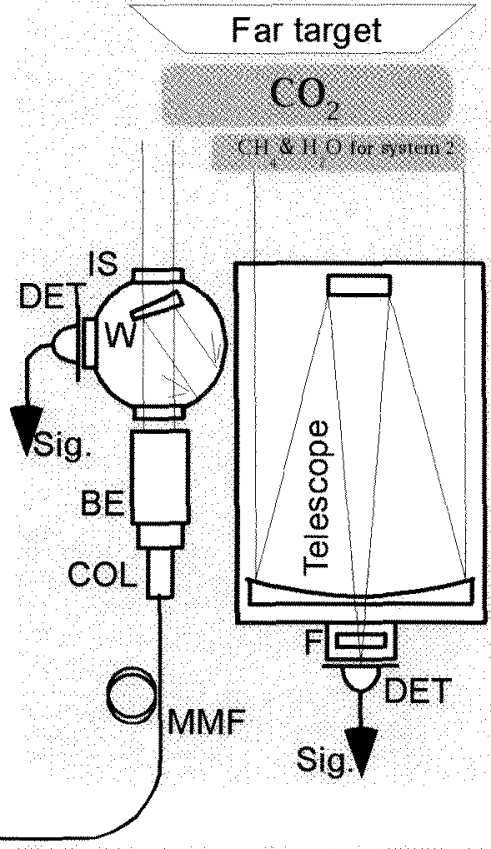




\section{Two horizontal open paths}



\section{Experimental results}

- Tuning range

- Two grating periods $(30.5 \& 31 \mu \mathrm{m})$

- 130 mm for NR (signal)

- $570 \mathrm{~mm}$ for MIR (idler)

- Output energy

- Optical-optical efficiency

- 16u signal, $7.6 \mu$ idler with 60u pump

- $39 \%$ lexcluding seed power)
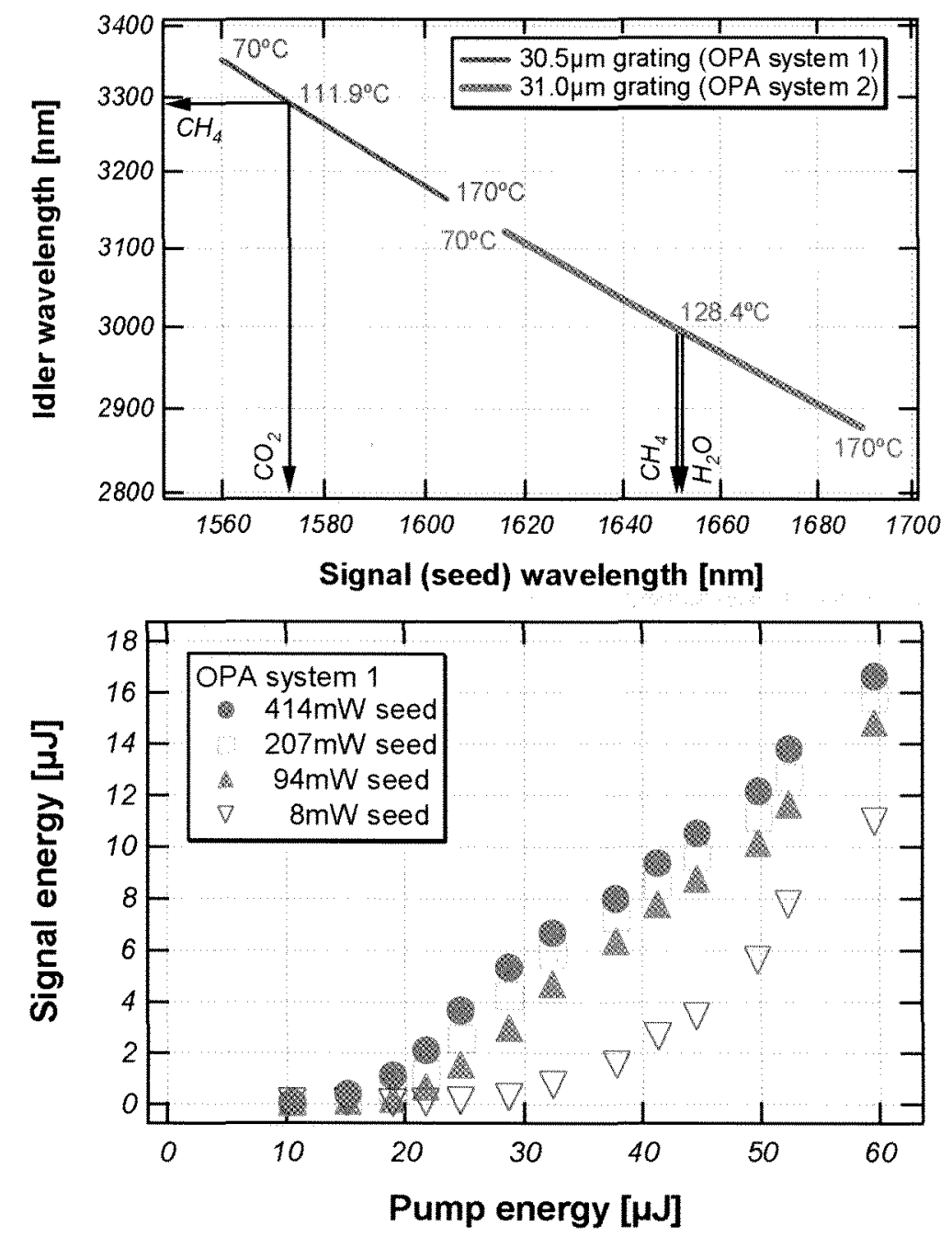


\section{Optical spectrum of output}

- Linewidth broadening

- Measured by a scanning etalon

- At low pump energy: 300MHz linewidth

- At high pump energy: $500 \mathrm{MHz}$ linewidth

- Mars's $\mathrm{CH}_{4}$ linewid th: $240 \mathrm{MHz}$

- Higher seed power ensures smooth tuning.

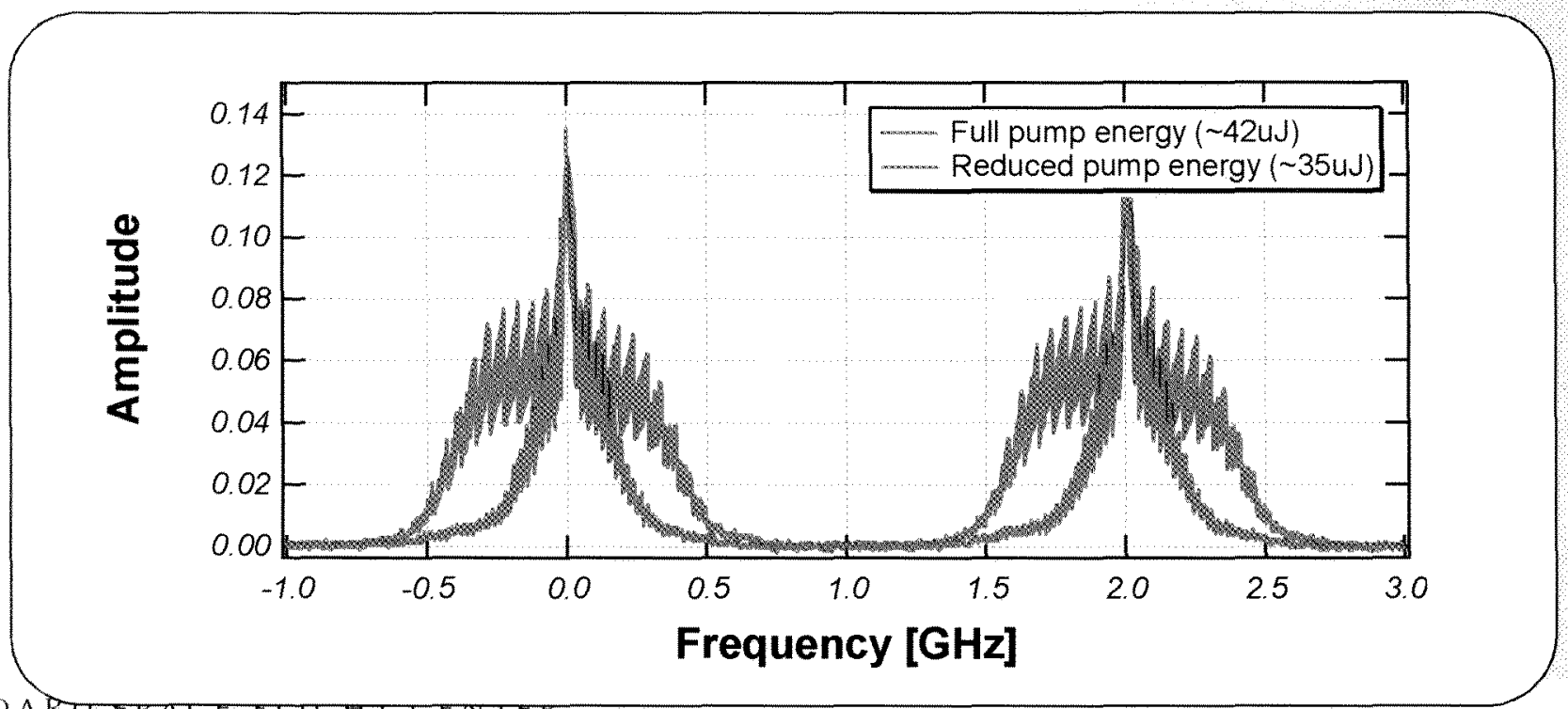




\section{Examples of scan data}

- Idler (3291nm)

- OPA system 2, near target

$-\mathrm{CH}_{4}$

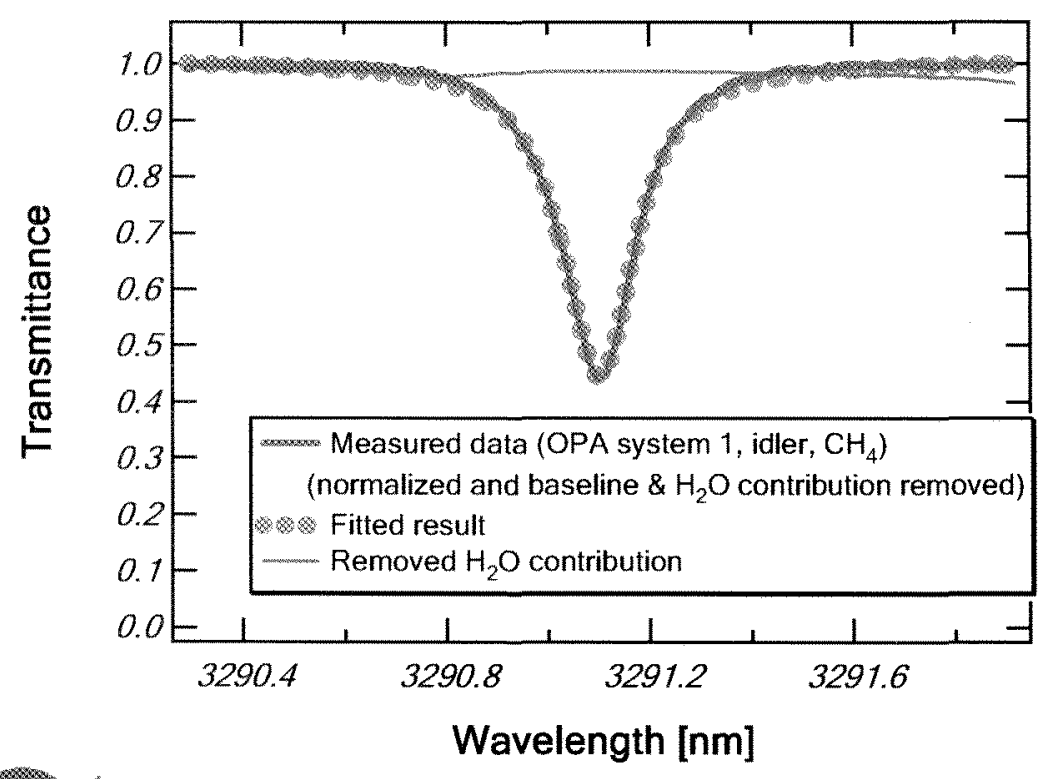

- Signal (1651nm)

- OPA system 1, far target

$-\mathrm{CH}_{4}$

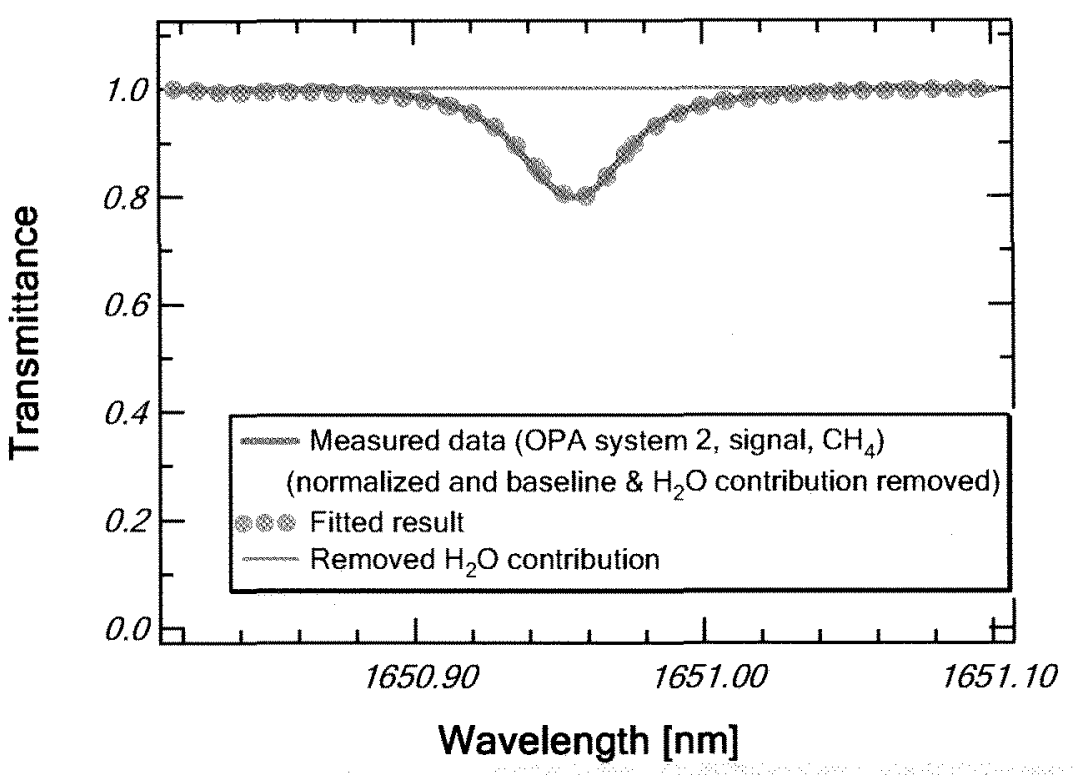




\section{Result - Methane}

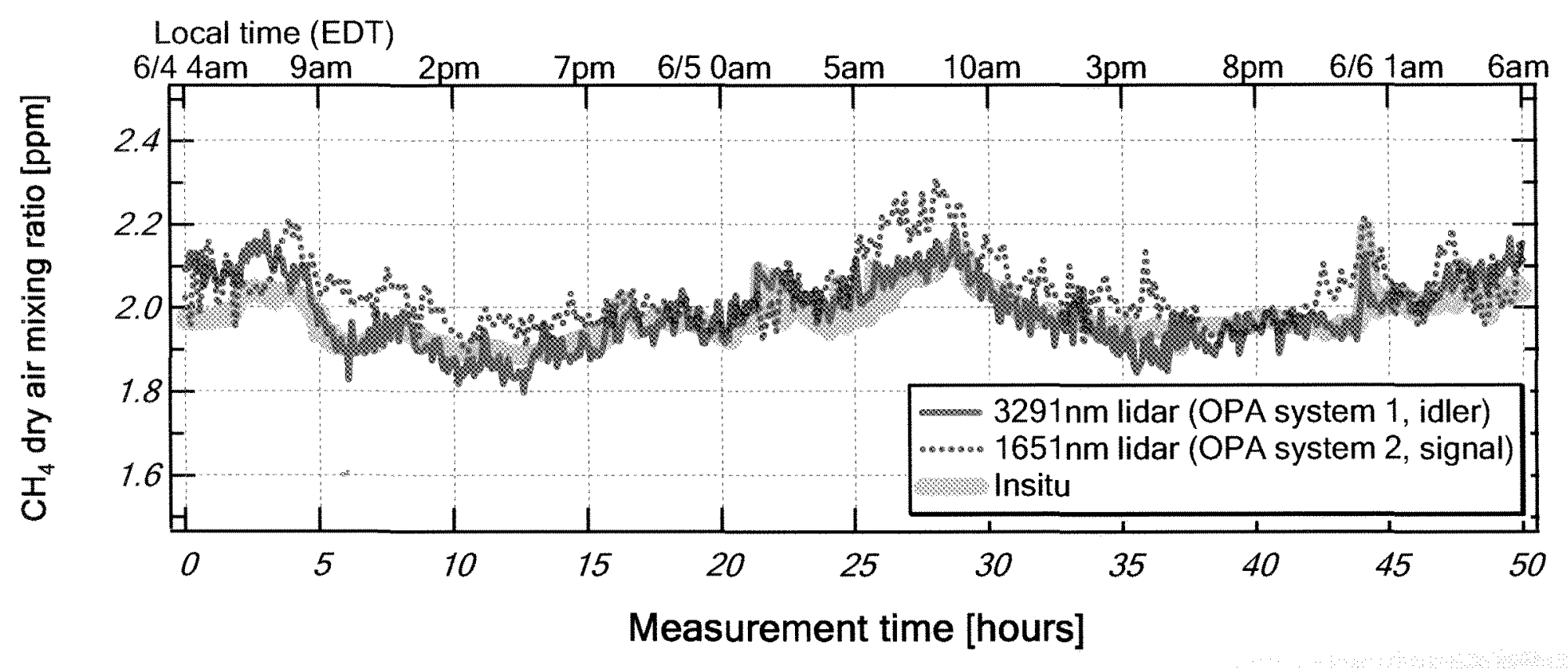




\section{Result - Carbon Dioxide}

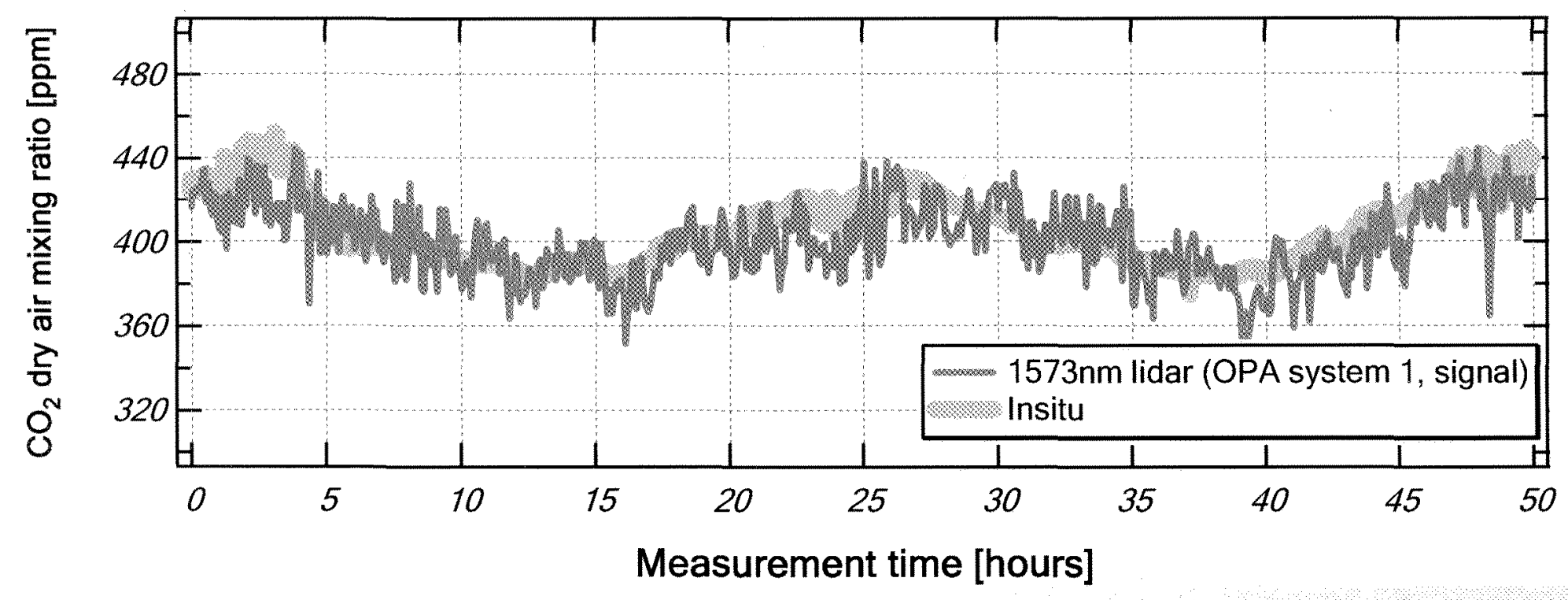




\section{Result - Water}

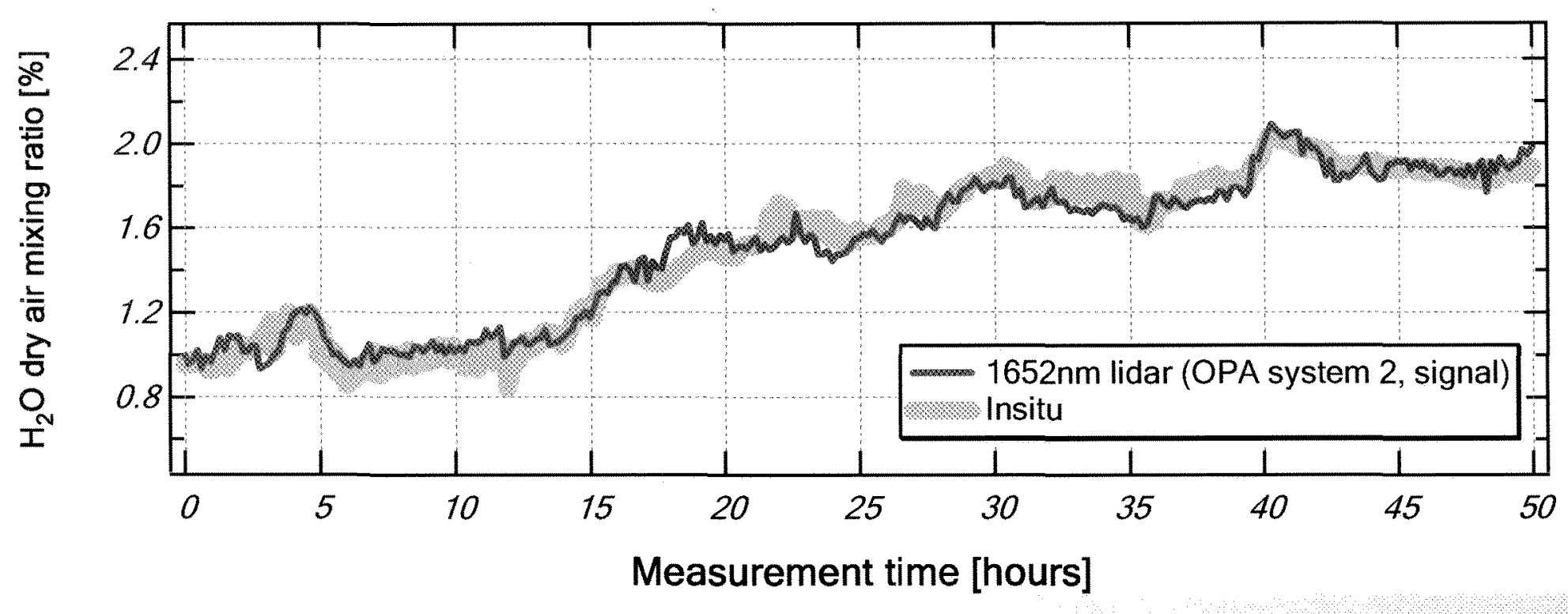




\section{Discussions}

- Airborne demonstration

- Will fly this week on NASA's DC-8

- $165 \mathrm{Inm} \mathrm{CH}_{4}$

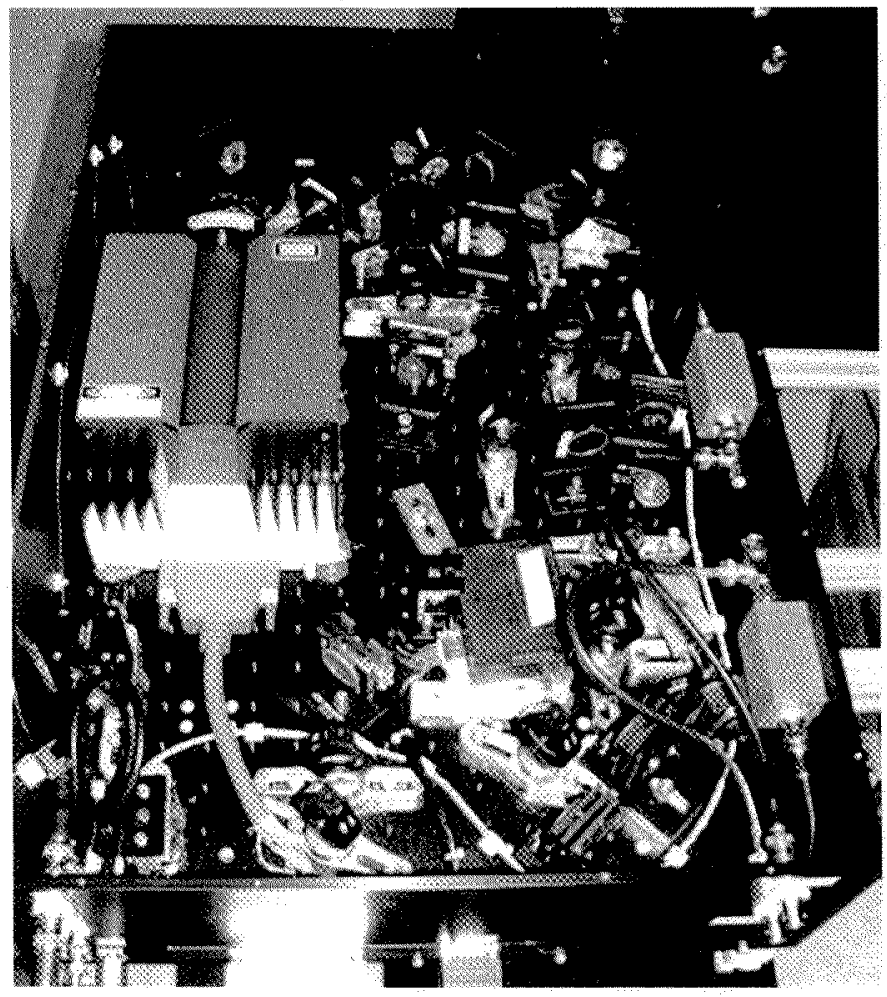

(2. 5) GODDARD SPACE FLIGHT CENTER
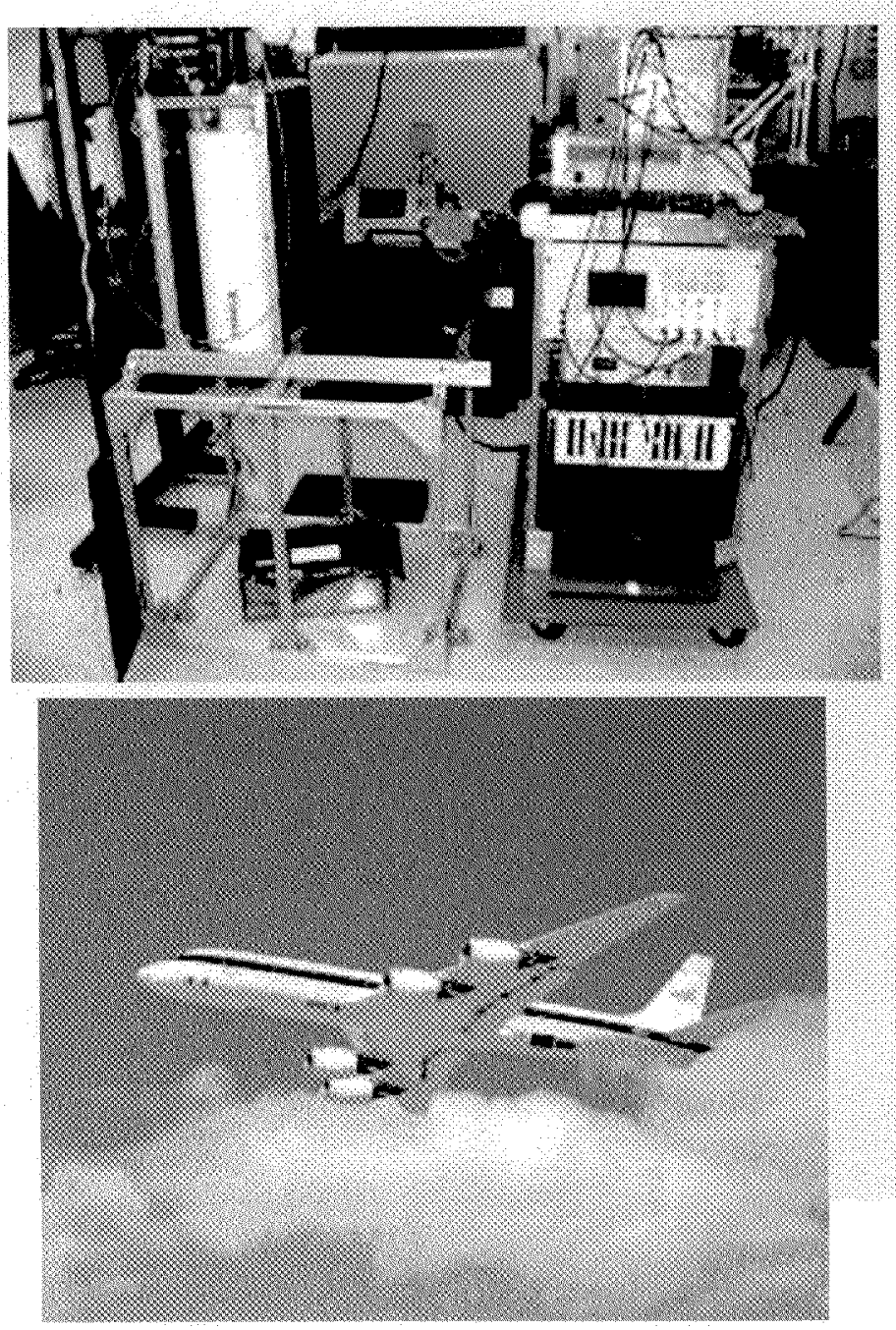


\section{Power scaling}

- Energy requirement for space applications

- x50 100 more output energy $(>300 \mu \mathrm{J})$

- Pump source

- mlevel, near single frequency

- Nd:YAG-based 1064nm

- Burst-mode Vb fiber amp

- Waveguide amp

- Seed source

- 1 W level required $(20 \mathrm{~mW} \times 100)$

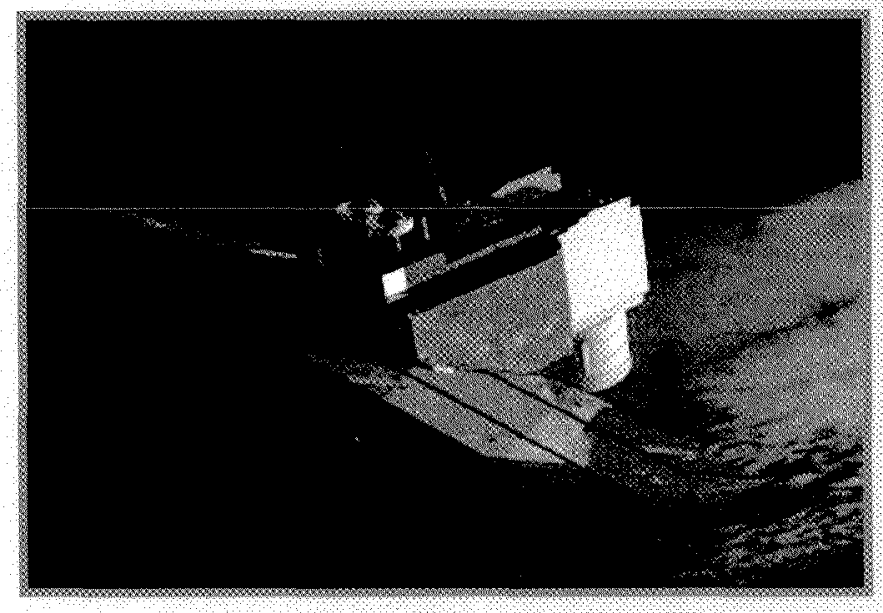

- Keeping same pump density \& pulse width ( 3 nsec)

- EDFA(1.5 $4 \mathrm{~m}$ ), other fiber amps, waveguide amp for $1.6 \mu \mathrm{m}$

- Dual stage OPA (OPA seeded by OPA output) 


\section{Conclusions}

- For future lidar missions

- Generation of high spatial resolution maps of trace gas

- OPA transmitter development

- Open-path demonstrations

- Both at NIR and MIR

- Wide \& smooth tunability shown by gas measurements

- Works to be done

- Airborne demonstrations

- Scaling up output power by using higher pump/seed powers

- Detector development at MIR 